\title{
Analysis of coal production automation system
}

\author{
Lingling HAN \\ Hebei Energy College of Vocation and Technology \\ Tangshan Hebei \\ China 063000
}

\begin{abstract}
The coal industrial transformation degree of relationship to the national level of development of productive forces, the automated construction of the coal industry is becoming a trend, the use of automated innovative technologies, energy-efficient equipment, computer-aided technology enables the construction of coal mine production automation,research and development, production and automation systems technology in the coal industry transformation plays a decisive role.
\end{abstract}

Keywords-Coal mines; production; automation; smart

\section{Production Automation System Overview}

Traditional craft, mine production system is divided into separate systems, operation and management also placed under a different part, to coordinate their respective relations mainly rely on manual scheduling, coordination effect is totally dependent on the quality of personnel and management level, due to lack of the close links between systems often follow-up system air operation, resulting in a waste of energy. Mine automation system to solve the automatic control system of coal production and auxiliary production can be achieved in the ground control center monitoring the production line process data and equipment operating status, and the provision of equipment for the mine production safety protection; remote control, reduce dangerous places to invest staff enhance mine safety production capacity [1].

\section{Automation of production system design}

Mine production automation system is a coal mine focus the system aspects involved mainly includes: the fully mechanized coal face control system the underground main op-belt control system, the main shaft hoisting control systems, ground coal washing system, these systems constitute a coal mine main production process, coal flow. One of the main ideas of the the coal flow aspects of the system integration of control is based on the location of the coal, how much to prepare the joint control starts and stops along the coal flow optimization control, frequency conversion means to achieve the maintenance, pilot production and coal capacity reduced to achieve energy case, when a link failure, according to the coal bin coal level, system status and reasonable emergency treatment automatic scheduling system, and try to ensure continuous coal flow under, reduce downtime

\section{A mechanized mining face control system}

Mechanized mining face control system design introduces the general planning, as well as the integration of the overall function of the system upgrade.
1) system function design

At least the following functions:

(1). Shearer, crushing machine, scraper conveyor, loader, telescopic belt sequence start and stop control, to achieve protection.

(2). To achieve, including current, voltage, temperature, insulation and other monitoring and protection for each motor.

(3). With voice communications and alarm functions.

(4). To achieve control of emulsion pump, spray pump.

(5). To achieve manually set control and remote mode switch in place

(6). With Ethernet communications functions, and receive control commands and send status information can be integrated automation standard.

Other automated mining face must automate follow-up of Moving, but this part of the design of hydraulic support, automatic the shift frame should have the following features:

(1). Pressure sensor and limit switch need to be set in each bracket, hydraulic support column and jack action agencies must adopt the electro-hydraulic drive. And the establishment of the whole electro-hydraulic control system.

(2). To achieve the single bracket neighboring support and the aircraft manual button and automation features, including front pillar neighboring support ascending, descending; After the column liter drop; to push slipped, Lycra; the front spar jacks extend and retract; telescopic beam jack stretch , shrink; care to help jack stretch, shrink; the side guard jacks extend and retract; jack telescopic pull slip.

(3). Automatically follow-up face mining progress with the group automatically control functions into a group automatically pushed slipped into groups automatically shift the frame, into the group automatically received care to help board, a group automatically and stretched nursing help boards, into a set of automatic extension stretching beam, into a set of automatic closing telescopic beam, and grouped automatically pull the rear downpipe.

\section{2) Systems integration functional design}

(1). Mining automation access the integrated automation system as a whole should be able to GIS information system linkage mining progress and strategy adjustments in a timely manner according to the changes of the coal seams and geological changes in the structure, through a comprehensive analysis of security information, disaster early warning of the 
extractive process may occur processing, and improve the safety of mining face.

(2). Accept to start the command from the control decision-making coal flow system as a whole, can be used as the starting system of the coal flow system, the mining area after its coal bunkers and underground transport belt system linkage control, control the decision-making system based on the mining area positions in the coal storage capacity and mechanized mining a coal speed and capacity of the system, timely start underground belt transport system can continue to run in downhole belt transport system and the subsequent coal stream online system failure or problem suspend the running or restart operation automatically, thereby improving the entire coal flow system efficiency and energy-saving operation.

(3). Monitoring the mining system to malfunction or anomalies timely feedback to control the decision-making system and coordination between the system automatically set the treatment plan, and in a timely manner will automatically publish to the various functional departments and the responsible person, in order to facilitate the fast and accurate decision-making.

(4). System based on extractive system equipment operation, statistics and analysis, the analysis of various equipment the loss cycle and loss of reason, targeted to develop efficient equipment operation and equipment management mechanism, the maximum possible increase in equipment operating years of cost savings [2].

\section{B Underground Master Air Waybill belt control system}

\section{1) The overall design}

The main design idea of the program is realized on the foundation of centralized control of each single belt to achieve the the belt joint optimization of the entire underground main transport of control of operation and protection of a single belt and if deviation, Pull String, smoke, skidding, the vertical tear tension, temperature, and so on all completed by the centralized control system of a single belt is not included in the design. The final optimization run unattended underground main op belt.

\section{2) System structure and function design}

The underground main transported belt control system structure shown in Figure 1.

(1). Able to automatically control the decision-making system command to start and stop the belt transport system changes based on the coal reserves of coal bunker on the position of the main shaft hoisting system linkage atresia.

(2). Performance statistics between the belt as the capacity and operational efficiency, the development of the belt between the optimized operation strategy, including the start and stop time between the start and stop of priority, and through real-time and reliable monitoring of coal flow position along the coal belt flow starts and stops, reducing the belt transport system invalid run time, to improve the efficiency of belt transport system, and achieve energy-saving effect.

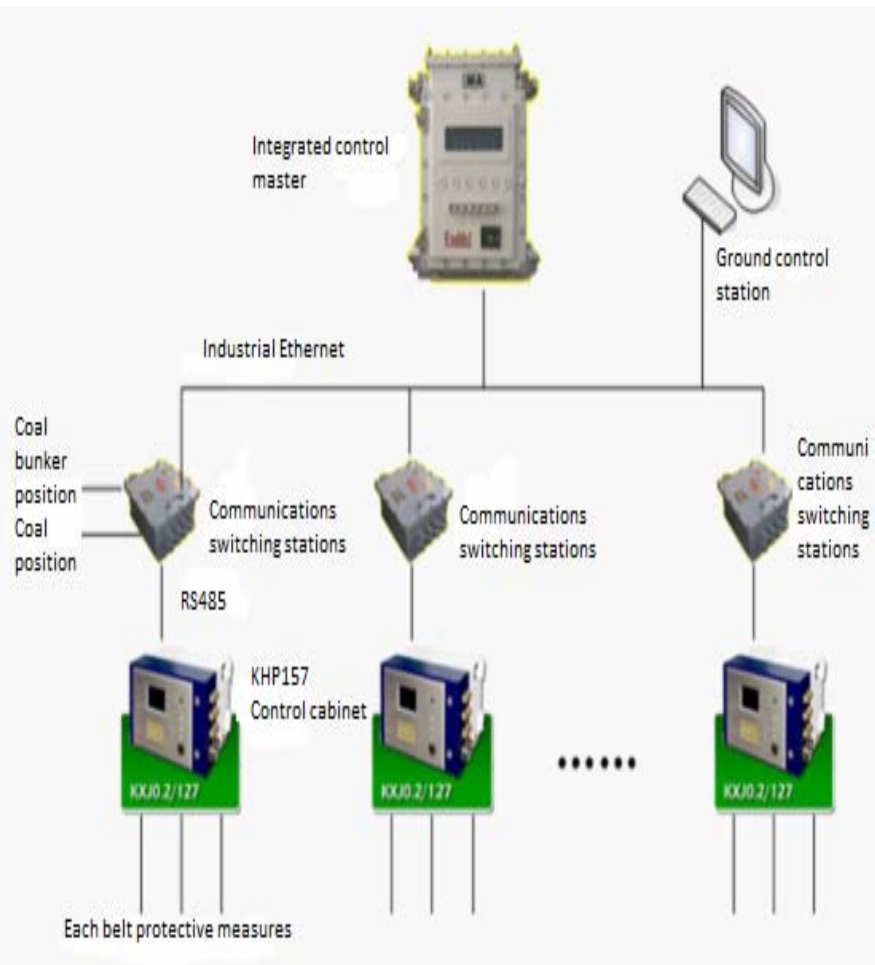

Figure 1. The control system structure figure of the main belt under the mine

(3). Establish control model of the underground belt transport to develop a reasonable joint atresia operating rules, according to the characteristics of the mine's coal flow system, with node coal bunker coal bit latch to achieve in the part of the belt failure or downtime each kinds of automatic plan processing mechanisms.

(4). According to the wear and tear of the belt transport system equipment and use of comparative method to analyze the reasons of the loss and issued recommendations on equipment maintenance and overhaul plan in a timely manner.

(5). Of belt transport system failures and anomalies by setting the treatment plan to perform the operation, and timely information using intelligent telephone alarm system released to the relevant departments and responsibilities.

(6). Achieve the mining district scalable linkage control of the tape machine (provided that the tape machine control system into the comprehensive automation network platform)

All belt of ground to achieve a key to start and stop, unattended underground transport belt.

\section{Main shaft hoist control system}

The main shaft hoist control system has completed construction of detailed technical solutions, the program is no longer only describes the main well integrated into the overall platform extensions [3].

(1). Control of the decision-making system based on coal reserves of coal bunker on the position of the main shaft hoisting latching control, to avoid the main shaft no-load or 
half load run, try to make the main shaft hoist load is more than $90 \%$, and improve the main shaft enhance the efficiency of the machine, the purpose of economic operation.

(2). Control decision-making system of the main shaft hoisting machine speed curve and torque curve analysis of the main shaft hoisting machine the optimal operating parameters (acceleration and deceleration, paragraphs running distance and speed, etc.), while shorter upgrade time, try reduce the impact of the machinery and equipment, while maximizing hoist the average power factor, to achieve the capacity to enhance energy saving double benefit.

(3). Main shaft system failure or abnormal control of the decision-making system other belt system according to various positions on the amount of coal will set plans for control, both to ensure that does not appear in the main shaft system failure during wasteful excess capacity, Also ensure fault recovery is running in the shortest possible time to restore the overall system of the coal flow.

\section{D ground coal - washing system}

(1).Changes according to the main shaft coal bin coal reserves ground production system to automatically start and stop.

(2). Control the decision-making system statistics between the belt capacity and operating efficiency, the development of optimized operation strategy between the belt, including the start and stop time between the start and stop of priority, invalid belt transport system to reduce the run time, increase the belt the efficiency of the transportation system, and achieve energy-saving effect.
(3). The belt drive motor with inverter control, based on the lifting capacity of the main shaft, the main coal bin coal level, the ability of the loading system, the speed of adjustment, as much as possible to achieve a continuous and economic operation.

\section{Conclusion}

Given the importance of coal mine safety in high-yield and efficient mine mechanized mining face, application production automation system, the system of centralized control, high-speed transmission. Accurate judgment on various issues on the safety management of coal production, equipment operation, production scheduling, and emergency handling ability. A safe, reliable, simple structure, convenient, scalability, maintenance technical characteristics, the various types of subsystems integrated into a unified transmission platform, and the application of new equipment to protect the coal mine safety, high-yield, efficient, automated production, a substantial increase in the coal mine production ability and safety management level.

\section{References}

[1] Sun Zhongrun; automation technology in mine production control application; mining safety and environmental protection in 2004 thirty-first volume fifth issue

[2] Wang Yong; China Coal Mine Comprehensive Automation

[3] Tan Dejian; China coal mine automation development strategy; the eighteenth session of the national coal mine automation academic annual meeting of China Coal Society automation professional committee conference on 2008 